\title{
Localization of ORC1 during the cell cycle in human leukemia cells
}

\author{
Frederick D. Coffman ${ }^{\mathrm{a}, *}$, Mai-Ling Reyes ${ }^{\mathrm{b}}$, Monique Brown ${ }^{\mathrm{c}}$, W. Clark Lambert ${ }^{\mathrm{a}}$ and Stanley Cohen ${ }^{\mathrm{a}}$ \\ ${ }^{a}$ Department of Pathology and Laboratory Medicine, UMDNJ - New Jersey Medical School, Newark, NJ, USA \\ ${ }^{\mathrm{b}}$ Jersey City Medical Center, Jersey City, NJ, USA \\ ${ }^{\mathrm{c}}$ Sanofi Pasteur, Discovery Drive, Swiftwater, PA, USA
}

Received: July 21, 2011

Accepted: October 7, 2011

\begin{abstract}
The interaction of the origin recognition complex (ORC) with replication origins is a critical parameter in eukaryotic replication initiation. In mammals the ORC remains bound except during mitosis, thus the localization of ORC complexes allows localization of origins. A monoclonal antibody that recognizes human ORC1 was used to localize ORC complexes in populations of human MOLT-4 cells separated by cell cycle position using centrifugal elutriation. ORC1 staining in cells in early G1 is diffuse and primarily peripheral. As the cells traverse G1, ORC1 accumulates and becomes more localized towards the center of the nucleus, however around the G1/S boundary the staining pattern changes and ORC1 appears peripheral. By mid to late $\mathrm{S}$ phase ORC1 immunofluorescence is again concentrated at the nuclear center. During anaphase, ORC1 staining is localized mainly in the pericentriolar regions. These findings suggest that concerted movements of origin DNA sequences in addition to the previously documented assembly and disassembly of protein complexes are an important aspect of replication initiation loci in eukaryotes.
\end{abstract}

Keywords: DNA replication, replication origin, ORC, nuclear localization, cell cycle

\section{Introduction}

In mammalian cells, the initiation of DNA replication appears to occur in close proximity to the nuclear matrix [1, 3, 8, 17, 23, 25]. This has been shown by several approaches, including pulse chase experiments and by fluorescence microscopy following the incorporation of fluorescent nucleotide analogs into nascent DNA. Parallel investigations revealed that the protein complexes that mediate replication were not evenly distributed across the nuclear matrix but were concentrated in large multi-protein complexes termed replication factories $[1,3,16]$. Each cell contains several hundred of these factories, and each factory is responsible for the initiation of replication that occurs

${ }^{*}$ Corresponding author: Frederick D. Coffman, Department of Pathology and Laboratory Medicine, UMDNJ - New Jersey Medical School, 185 S. Orange Avenue, Newark, NJ 07103, USA. Tel.: +1(973) 972 2861; Fax: +1(973) 972 7293; E-mail: coffmafd@umdnj.edu. at hundreds to thousands of individual replication origin sequences. Within any one such factory all origins initiate at the same time; however different replication factories initiate at different points during $\mathrm{S}$ phase. An elegant study using confocal microscopy and dual fluorescent labels to differentiate replication from transcription revealed that the nucleus was spatially organized during S phase [32]. At any one time 18-22 distinct regions were involved in DNA replication, and 15-19 different regions were involved in transcription. There was virtually no overlap between regions involved in replication and transcription, indicating that the processes were spatially separate. Examination of nuclei at different times during $S$ phase showed regions which were involved in transcription while neighboring regions underwent replication, then these regions stopped transcription to undergo replication while the newly replicated regions commenced transcriptional activity. Replication in the nucleus appears both spatially and temporally ordered, with 
different nuclear regions coordinated in some manner with respect to the processes of transcription and chromosomal replication $[4,25,32]$.

The molecular interactions within eukaryotic replication origins occur within this overall structure. In yeast, the six proteins of the origin recognition complex (ORC) and the MCM proteins bind to origin sequences throughout the cell cycle $[19,28,33]$. These complexes sequentially recruit a series of proteins that result in a particular replication initiation site being opened by the MCM helicase activity and bound by the replicative polymerases. Additionally, the melting of the DNA double helix promotes a conformational change in the ORC associated with a post-replicative state that acts to prevent reinitiation of replication at that specific site [19].

Homologues of the yeast ORC and MCM proteins have been found in higher eukaryotes and likely perform similar functions in the regulation of replication initiation [10]. One noticeable difference is that in mammalian cells the ORC either dissociates or changes its manner of association with origins during mitosis and early G1. Origins in isolated nuclei taken from mitotic and early G1 cells are incapable of initiating replication when incubated with Xenopus extracts, while origins in isolated nuclei taken from cells in other cell cycle phases readily initiate replication upon the addition of Xenopus extracts [24].

In the present study, we utilized immunofluorescence to localize ORC1, a key ORC component, in populations of human MOLT- 4 cells separated by cell cycle position using centrifugal elutriation. The elutriation technique allows separation of cells by cell cycle position without the artifacts in gene expression introduced by cell synchronization methods [13]. As cells moved through the cell cycle, the localization of ORC1 shifted, suggesting changes in the localization of ORC-bound origin sequences. During anaphase, ORC1 appears concentrated in the pericentriolar regions.

\section{Materials and methods}

\subsection{Reagents}

Buffers, salts, and propidium iodide were obtained from Sigma (St. Louis, MO.). Murine monoclonal antibody clone 7F6/1 (anti-human ORC1) was obtained from Lab Vision (Fremont CA). Anti-human cyclin
E and anti-human cyclin A were obtained from Santa Cruz Biotechnology (Santa Cruz, CA). Secondary antibodies conjugated to ALEXA fluors were obtained from Molecular Probes (Eugene, Oregon). Nunc chamber slides were obtained from Sigma.

\subsection{Cells and tissue culture}

The human T cell leukemia MOLT-4 cell line was maintained in RPMI 1640 (GIBCO) supplemented with $10 \%$ fetal bovine serum (GIBCO, Hyclone), glutamine (Sigma), penicillin and streptomycin (Sigma). Cells were grown in a $37^{\circ} / 5 \% \mathrm{CO} 2$ incubator and passaged when cell densities reached 5-8 $\times 10^{5}$ cells $/ \mathrm{ml}$.

\subsection{Centrifugal elutriation}

A Beckman JE-5.0 elutriation rotor fed by a Masterflex pump (Cole Parmer Model 7520-25) was washed with $250 \mathrm{ml} 70 \%$ ethanol followed by $250 \mathrm{ml}$ PBSEDTA elutriation buffer $\left(10 \mathrm{mM} \mathrm{Na} 2 \mathrm{HPO}_{4}, 137 \mathrm{mM}\right.$ $\mathrm{NaCl}, 2.7 \mathrm{mM} \mathrm{KCl}, 2 \mathrm{mM}$ EDTA, pH 7.4). The centrifuge was started and the rotor was maintained at $2700 \mathrm{rpm}$ and $18^{\circ} \mathrm{C}$ throughout the experiment. MOLT- 4 cells $\left(1.44 \times 10^{8}\right.$ cells $)$ were harvested by centrifugation, resuspended in $10 \mathrm{ml}$ elutriation buffer, and loaded onto the elutriation rotor at a pump speed of $18 \mathrm{ml} / \mathrm{min}$. Fractions $(150 \mathrm{ml})$ were collected at pump speeds of 23, 27, 30, 38, 45, 50 and $70 \mathrm{ml} / \mathrm{min}$. Each fraction was pelleted and resuspended in $3 \mathrm{ml}$ chilled PBS-EDTA. Aliquots were removed for cell counting and flow cytometric analysis. For immunofluorescence studies, cells were either directly added to chambers on slides as described below or fixed in ice cold $70 \%$ ethanol and stored at $4{ }^{\circ} \mathrm{C}$ until used for making slides. Fraction 1 (collected at $23 \mathrm{ml} / \mathrm{min}$ ) usually contained too few cells to use for slides.

\subsection{Immunofluorescence}

Nunc chamber slides were treated with $5 \mathrm{mM}$ poly-L-lysine overnight at room temperature. Cells $\left(2-5 \times 10^{5}\right.$ cells in $0.15 \mathrm{ml}$ media) were added to the chambers and incubated for 1 hour in a $37^{\circ} \mathrm{C}$ incubator. An equal volume $(0.15 \mathrm{ml})$ of $4 \%$ paraformaldehyde was added and the slide incubated 10 minutes at room temperature. The liquid was aspirated, a second $0.15 \mathrm{ml}$ aliquot of $4 \%$ paraformaldehyde was added to the chambers, and the slide incubated 10 minutes 
at room temperature. The liquid was aspirated and the fixed cells were permeabilized by the addition of $0.15 \mathrm{ml}$ phosphate buffered saline (PBS) containing $0.05 \%$ Triton $\mathrm{X}-100$ and allowed to incubate 10 minutes at $37^{\circ} \mathrm{C}$. The detergent is removed by three PBS washes, then PBS containing 5\% serum is added and the slides incubated at $37^{\circ} \mathrm{C}$ for 1 hour to block nonspecific protein binding sites. Followed by a PBS wash, the primary antibody is added $(1: 100$ dilution in PBS) and incubated $1-3$ hours at $37^{\circ} \mathrm{C}$. The slide is washed three times with PBS, then the fluorochromeconjugated second antibody (1:100 dilution in PBS) is added and the slide incubated 1 hour at $37^{\circ} \mathrm{C}$. The slides are washed three times with PBS, allowed to air dry, then the chambers and silicon gaskets removed from the slides, Perma-Mount applied and the slide sealed with a cover slip. All steps using fluorochrome labels are performed under safe light conditions, and fluorochrome-labelled slides are stored in foil-wrapped containers.

\section{Results}

\subsection{ORC1 position in $G 1, S$ and $G 2$ phase cells}

In Figs. 1 and 3, six elutriated fractions are depicted containing cells in different phases of the cell cycle. The disproportionate size of the nucleus in MOLT-4 cells is illustrated in Fig. 2; nearly all of the visible cell area, save for a thin crescent on one side of the cell, represents the cell nucleus. In cells in the earliest stages of $\mathrm{G} 1$, the ORC1 immunofluorescence is diffuse with localized areas of intense staining at the nuclear periphery. As cells progress through G1, the ORC1 immunofluorescence diminishes at the nuclear periphery and increases at the center of the nucleus, until by late $\mathrm{G} 1$ virtually all immunofluorescence is seen at the nuclear center (Fig. 3C). During this time the total ORC1 immunofluorescence increases, suggesting ongoing ORC1 synthesis in G1. In cells at the G1/S boundary or early $\mathrm{S}$ phase the majority of ORC1
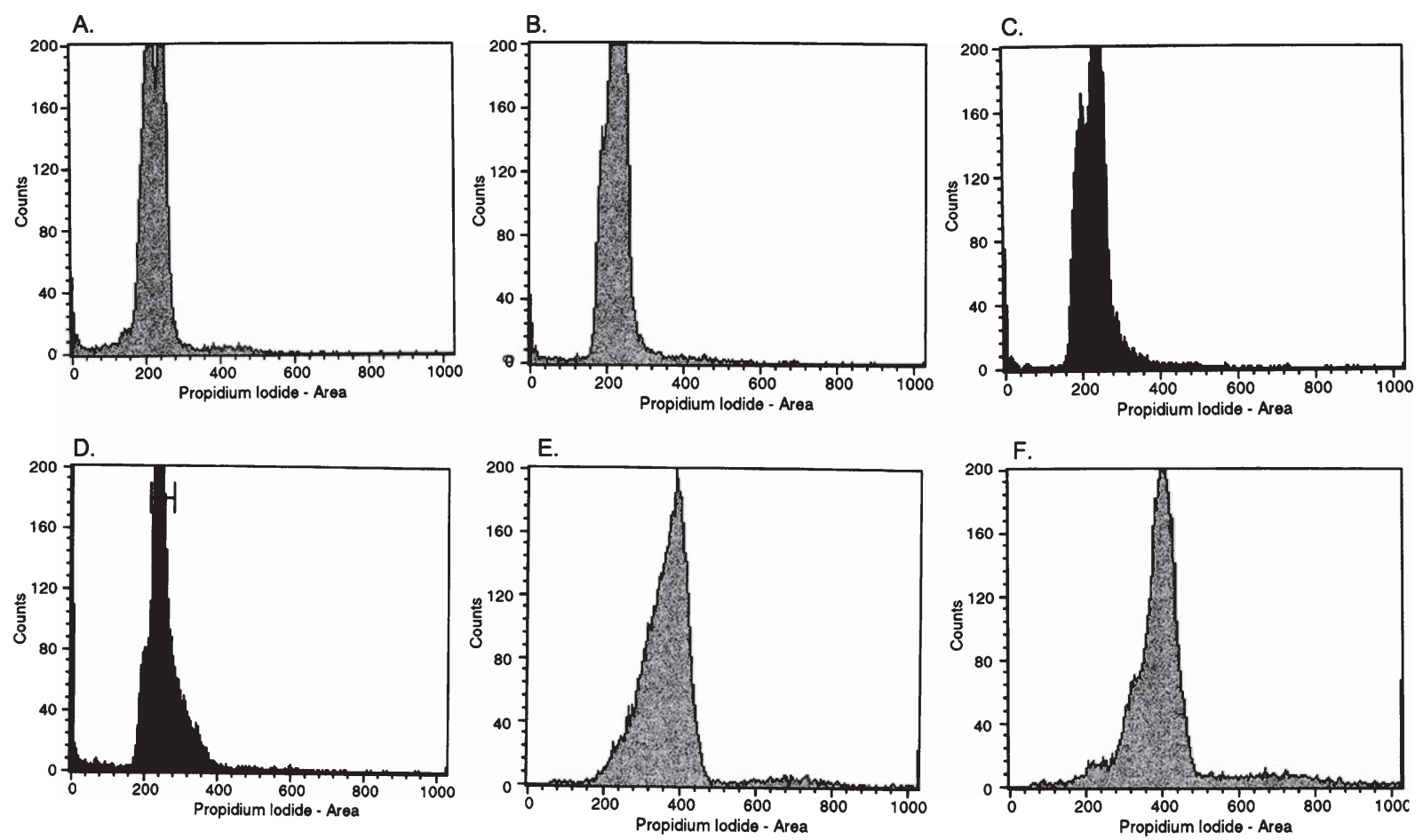

Fig. 1. FACS DNA profiles of cells separated using centrifugal elutriation. Proliferating, asynchronous MOLT-4 cells were separated using centrifugal elutriation into fractions that corresponded to cells in different phases of the cell cycle, and stained for DNA content using propidium iodide. A. Fraction 2, all cells are in early G1. B. Fraction 3, cells range from early to mid G1. C. Fraction 4, cells range from mid-G1 to late G1. D. Fraction 5, cells are at the G1/S boundary (late G1 - early S phase). E. Fraction 6, cells are in mid to late S phase. F. Fraction 7, cells are in $\mathrm{G} 2 / \mathrm{M}$. 


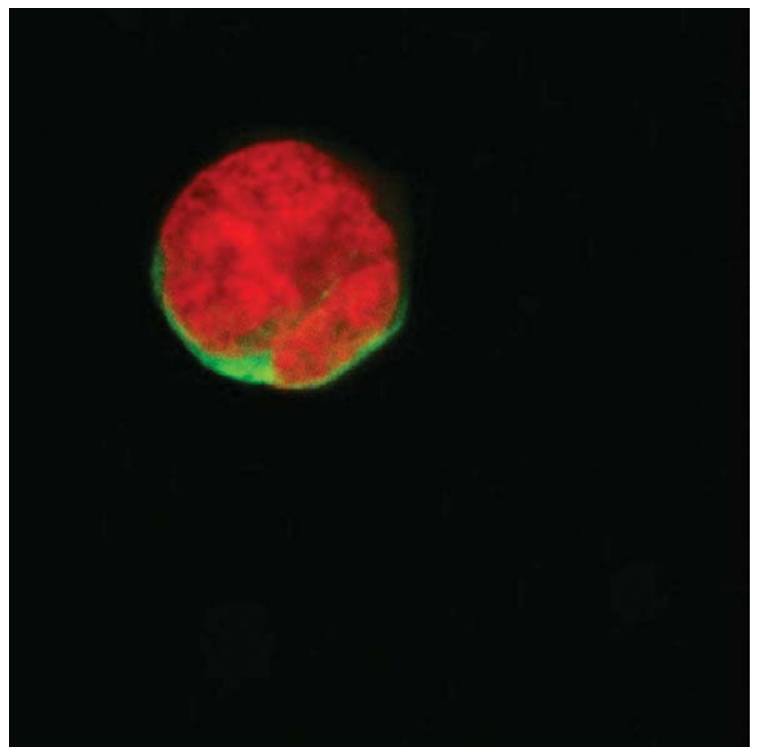

Fig. 2. Relatively small size of the cytoplasm compared to the nucleus in MOLT- 4 cells. MOLT- 4 cells were stained with a primary antibody recognizing the U1A ribonucleoprotein (which exists in both cytoplasmic and nuclear compartments) and a secondary antibody conjugated to Alexa Fluor 488 (green fluorescence) before chromatin was stained with propidium iodide (red fluorescence). The volume of the cell is primarily taken up by the nucleus, leaving a thin green crescent of cytoplasm visible on one side.

immunostaining has shifted back to the nuclear periphery, yet by mid to late $\mathrm{S}$ phase the principle ORC1 immunoflourescence is again found at the nuclear center. Cells in G2 show a more even distribution of ORC1 staining, although patches of ORC1 accumulation at the nuclear periphery may be seen.

\subsection{ORC1 localizes to the pericentriolar region during anaphase}

A small number of $\mathrm{G} 2 / \mathrm{M}$ cells contained two regions of ORC1 immunofluorescence at opposite sides of the nuclear periphery (Fig. 4A). This condition appeared to be transient and limited to cells that had progressed through mitosis to the point of cytokinesis, in other cells from this fraction the ORC1 immunofluorescence was distributed evenly around the nuclear periphery. To better visualize the chromatin in these cells, MOLT-4 cells were stained with hematoxylin and ORC-1 was visualized by a peroxidase staining (Fig. 4B). Cells containing the symmetric ORC1 immunofluorescence on two opposing sides of the nuclear periphery were identified by DNA staining as being in anaphase. In these cells ORC1 was localized primarily to the pericentriolar region.

\section{Discussion}

Previous results in yeast using origins that replicate at specific times during $\mathrm{S}$ phase have shown that late firing origins are associated with the peripheral nuclear matrix and early firing origins are distributed across the nuclear interior [15]. While the ORC1 staining in the MOLT-4 cells represents ORC bound to all origins, it is interesting that the majority of staining in early $\mathrm{S}$ phase is associated with the nuclear periphery. The majority of origins are associated with transcriptionally silent chromatin and this chromatin replicates late in $\mathrm{S}$ phase in eukaryotic cells $[14,21,29]$. The movement of origin sequences towards the nuclear interior as $S$ phase progresses parallels that seen in yeast as well [15]. Data from yeast experiments in which early and late firing origins are moved to different chromosomal positions indicate that context is critical in regulating origin activity [9]. Yeast origins bound to the nuclear periphery are prevented from initiating, and this parallel appears to hold in MOLT- 4 cells. Whether the migration to the nuclear center of the ORC1 staining during $\mathrm{S}$ phase represents the positioning of these origins in an active configuration, as suggested from the yeast model, remains to be shown.

Two observations were unexpected in light of previous studies using yeast. One is the migration of ORC1 during G1, in which the protein staining moved from the periphery to the nuclear center and back to the periphery prior to $\mathrm{S}$ phase onset. The MOLT-4 T lymphoblastic cells contain very little cytoplasm, the peripheral limits were assumed to be the nuclear periphery, however cytoplasmic localization of ORC1 at the extreme periphery cannot be excluded. A number of lines of experimental evidence indicate that replication initiation is regulated by interactions with nuclear matrix components $[2,5,11,12,18,20]$. If the positioning of late-firing origins at the nuclear periphery is necessary in part to prevent their activation in early $\mathrm{S}$ phase, it is unclear why these origins must move in concert through the nuclear center during G1. These movements may represent what has been described as a dynamic association of ORC1 with replication origins through the cell cycle or an "ORC1 cycle" [6, 7, 22]. They may also represent the sequential movement of DNA through spatially fixed replication factories, as 

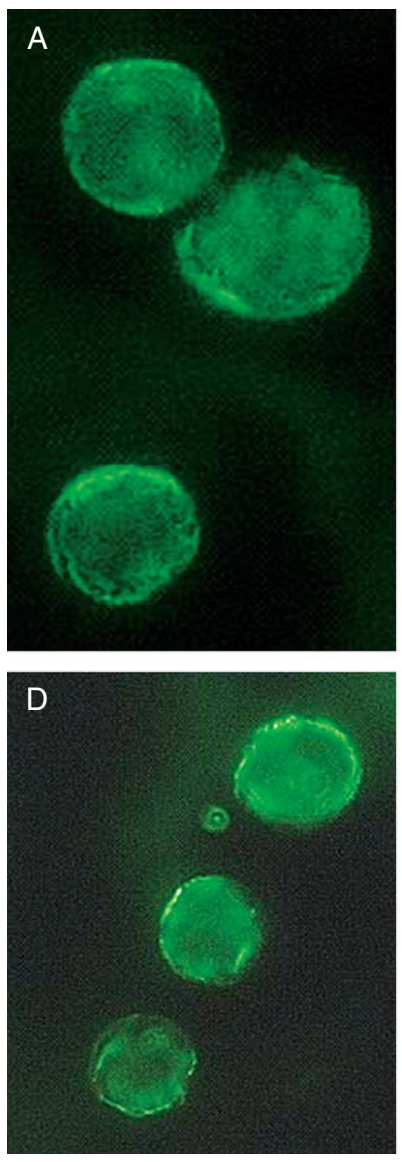
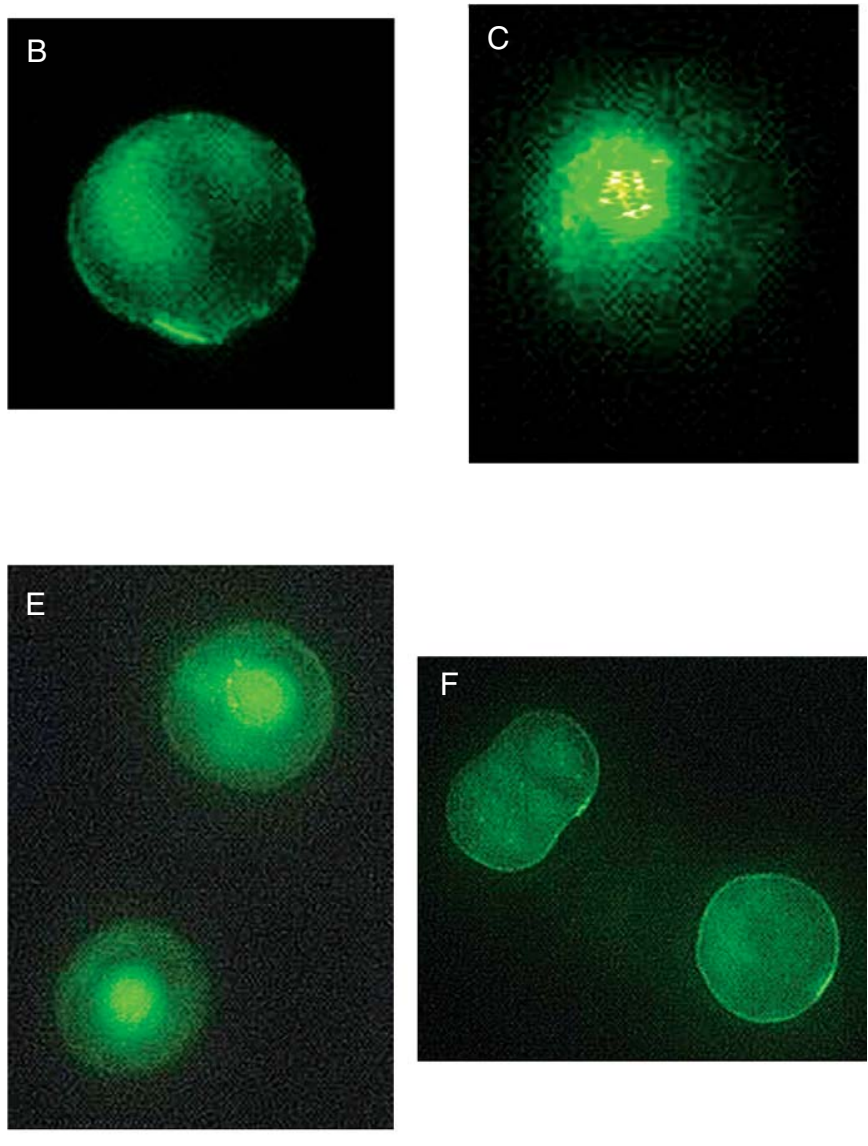

Fig. 3. Immunofluorescent staining for ORC1 in elutriated cells. Cells from the fractions described in Fig. 1 were fixed to the bottom of chamber slides and incubated sequentially with anti-ORC1 and then an ALEXA Fluor-conjugated secondary antibody. Immunostaining was visualized by fluorescence microscopy. A. Fraction 2, cells in early G1. B. Fraction 3, cells in early to mid G1. C. Fraction 4, cells in mid to late G1. D. Fraction 5, cells in late G1 - early S (G1/S boundary). E. Fraction 6, cells in mid to late S phase. F. Fraction 7, cells in G2/M.
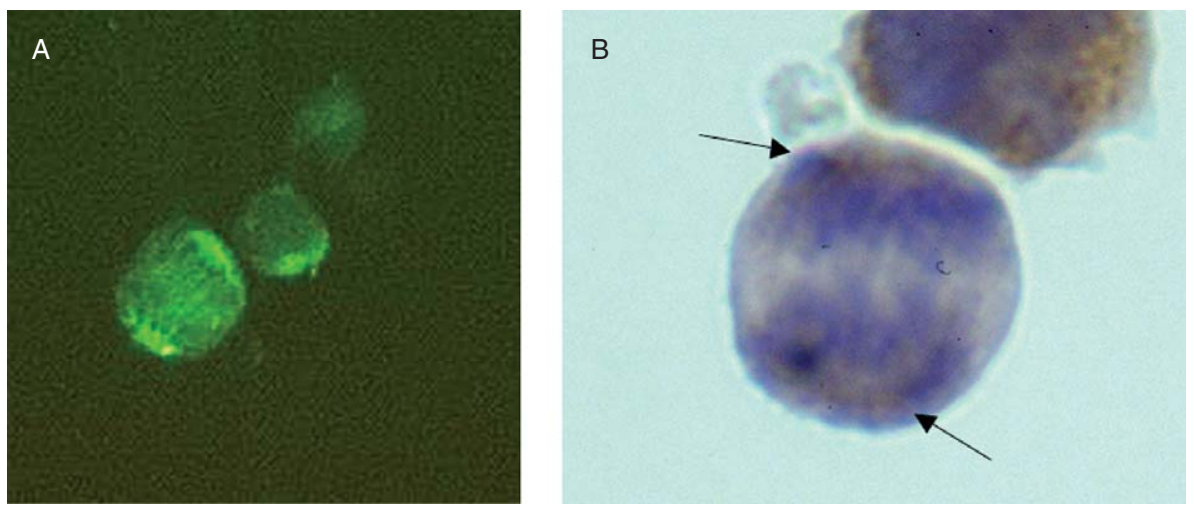

Fig. 4. ORC1 localization in anaphase cells. Cells A. Immunofluorescent staining of G2/M cells using anti-ORC1. B. G2/M cells stained with anti-ORC1 and peroxidase-conjugated second antibody and hematoxylin to visualize chromatin. Brown peroxidase staining is localized to the pericentriolar regions in anaphase cells (arrows). 
was recently documented in hepatic tissues undergoing regeneration [27].

Some of what is visualized in these experiments may be unique to tumor cells, or to this particular tumor cell line. The MOLT- 4 cell line was derived from a single case of acute lymphoblastic leukemia from a patient who had received prior chemotherapy, and carries a hypertetraploid chromosome number. Thus the nuclei of these cells contain significantly more DNA than their normal counterparts, and more than many tumor cells, which might affect the phenomena reported here. Tumor cell chromosomes often contain translocations and breakage, and the presence of extra chromatin in an already crowded nucleus may facilitate this type of DNA damage during replication or mitosis (Fig. 2 and [26]). As ORC1 provides a convenient marker to follow the pathway of newly replicated chromatin, experiments are in progress that will compare ORC1 movement in several lymphoid tumor cell lines with ORC1 movement in proliferating normal lymphocytes.

The pericentriolar localization of ORC1 during anaphase is also unexpected. A limited number of proteins specifically localize to this region, including actin and a telomere binding protein [30]. Recent evidence suggests ORC1 interacts with TRF2 and may be involved in the regulation of telomere homeostasis, which may be linked to our observation [31]. It is also possible that pericentriolar positioning helps ensure that each daughter cell receives sufficient quantities of origin-binding proteins prior to cytokinesis and the reformation of the nuclear membrane. In bacteria, newly replicated origin sequences and their associated proteins migrate to opposite ends of the organism, in part to insure that each daughter organism receives an intact replication origin.

\section{References}

[1] R. Berezney, The nuclear matrix: A heuristic model for investigating genomic organization and function in the cell nucleus, J Cell Biochem 47 (1991), 109-123.

[2] J.J. Blow and R.A. Laskey, A role for the nuclear envelope in controlling DNA replication within the cell cycle, Nature 332 (1998), 546-548.

[3] P.R. Cook, The nucleoskeleton and the topology of replication, Cell 66 (1991), 627-635.

[4] P.R. Cook, The organization of replication and transcription, Science 284 (1999), 1790-1795.

[5] L.S. Cox, DNA replication in cell-free extracts from Xenopus eggs is prevented by disrupting nuclear envelope function, $J$ Cell Science 101 (1992), 43-53.
[6] M.L. DePamphilis, The, 'ORC cycle': A novel pathway for regulating eukaryotic DNA replication, Gene 310 (2003), 1-15.

[7] M.L. DePamphilis, Cell cycle dependent regulation of the origin recognition complex, Cell Cycle 4 (2005), 70-79.

[8] P.A. Dijkwel and J.L. Hamlin, Origins of replication and the nuclear matrix: The DHFR domain as a paradigm, Int Rev Cytology 162A (1995), 455-484.

[9] B.M. Ferguson and W.L. Fangman, A position effect on the time of replication origin activation in yeast, Cell 68 (1992), 333-339.

[10] K.A. Gavin, M. Hidaka and B. Stillman, Conserved initiator proteins in eukaryotes, Science 270 (1995), 1667-1671.

[11] D.M. Gilbert, H. Miyazawa and M.L. DePamphilis, Sitespecific initiation of DNA replication in Xenopus egg extract requires nuclear structure, Mol Cell Biol 15 (1995), 2942-2954.

[12] D.M. Gilbert, Nuclear position leaves its mark on replication timing, J Cell Biol 152 (2001), F11-F15.

[13] J. Gong, F. Tragonos and Z. Darzynkiewicz, Growth imbalance and altered expression of cyclins B1, A, E. and D3 in MOLT4 cells synchronized in the cell cycle by inhibitors of DNA replication, Cell Growth Differ 6 (1995), 1485-1493.

[14] R. Hand, Eukaryotic DNA: Organization of the genome for replication, Cell 15 (1978), 317-325.

[15] P. Heun, T. Laroche, M.K. Raghuraman and S.M. Gasser, The positioning and dynamics of origins of replication in the budding yeast nucleus, J Cell Biol 152 (2001), 385-400.

[16] P. Hozak, A.B. Hassan, D.A. Jackson and P.R. Cook, Visualization of replication factories attached to a nucleoskeleton, Cell 73 (1993), 361-373.

[17] D.A. Jackson and P.R. Cook, Replication occurs at a nucleoskeleton, EMBO J 5 (1986), 1403-1410.

[18] S.J. Lawlis, S.M. Keezer, J.R. Wu and D.M. Gilbert, Chromosome architecture can dictate site-specific initiation of DNA replication in Xenopus egg extracts, J Cell Biol 135 (1996), 1207-1218.

[19] M. Lei and B.K. Tye, Initiating DNA synthesis: From recruiting to activating the MCM complex, J Cell Science 114 (2001), 1447-1454.

[20] G.H. Leno, C.S. Downes and R.A. Laskey, The nuclear membrane prevents replication of human G2 nuclei but not G1 nuclei in Xenopus egg extract, Cell 69 (1992), 151-158.

[21] F. Li, J.H. Chen, M. Izumi, M.C. Butler, S.M. Keezer and D.M. Gilbert, The replication timing program of the Chinese hamster beta-globin locus is established coincident with its repositioning near peripheral heterochromatin in early G1 phase, $J$ Cell Biol 154 (2001), 283-292.

[22] A.J. McNairn, Y. Okuno, T. Misteli and D.M. Gilbert, Chinese hamster ORC subunits dynamically associate with chromatin throughout the cell-cycle, Exp Cell Res 308 (2005), 345-356.

[23] H. Nakayasu and R. Berezney, Mapping replicational sites in the eukaryotic cell nucleus, J Cell Biol 108 (1989), 1-11.

[24] D.A. Natale, C.J. Li, W.H. Sun and M.L. DePamphilis, Selective instability of Orc1 protein accounts for the absence of functional origin recognition complexes during the M-G(1) transition in mammals, EMBO J 19 (2000), 2728-2738.

[25] J.M. Ortega and M.L. DePamphilis, Nucleoskeleton and initiation of DNA replication in metazoan cells, J Cell Science 111 (1998), 3663-3673.

[26] B.A.J. Ponder, Cancer genetics, Nature 411 (2001), 336-341. 
[27] J.C. Rivera-Mulla, R. Hernandez-Munoz, F. Martinez and A. Aranda-Anzaldo, DNA moves sequentially towards the nuclear matrix during DNA replication in vivo, BMC Cell Biol 12 (2011), 3-19.

[28] A. Rowles and J.J. Blow, Chromatin proteins involved in the initiation of DNA replication, Curr Op Gen Dev 7 (1997), $152-157$.

[29] S. Selig, K. Okumura, D.C. Ward and H. Cedar, Delineation of DNA replication time zones by fluorescence in situ hybridization, EMBO J 11 (1992), 1217-1225.

[30] S. Smith and T. de Lange, Cell cycle dependent localization of the telomeric PARP, tankyrase, to nuclear pore complexes and centrosomes, J Cell Sci 112 (1999), 3649-3656.
[31] Y. Tatsumi, K. Ezura, K. Yoshida, T. Yugawa, M. NarisawaSaito, T. Kiyono, S. Ohta, C. Obuse and M. Fujita, Involvement of human ORC and TRF2 in pre-replication complex assembly at telomeres, Genes to Cells 13 (2008), 1045-1059.

[32] X. Wei, J. Samarabandu, R.S. Devdhar, A.J. Siegel, R. Acharya and R. Berezney, Segregation of transcription and replication sites into higher order domains, Science 281 (1998), 1502-1505.

[33] M.Zannis-Hadjopoulos and G.B. Price, Regulatory parameters of DNA replication, Crit Rev Euk Gene Exp 8 (1998), 81-106. 


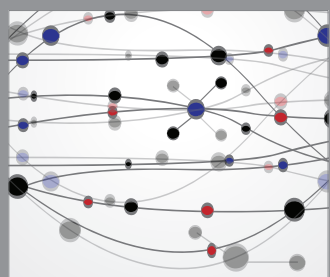

The Scientific World Journal
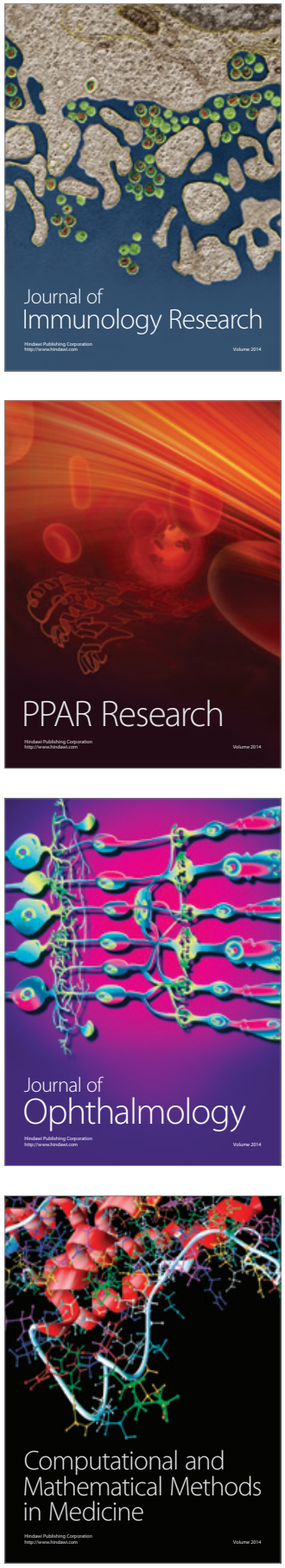

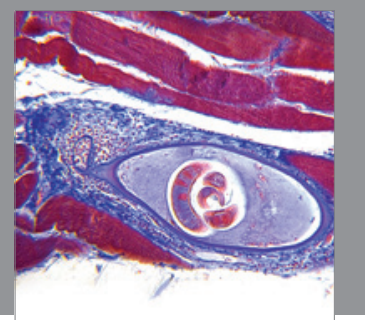

Gastroenterology

Research and Practice
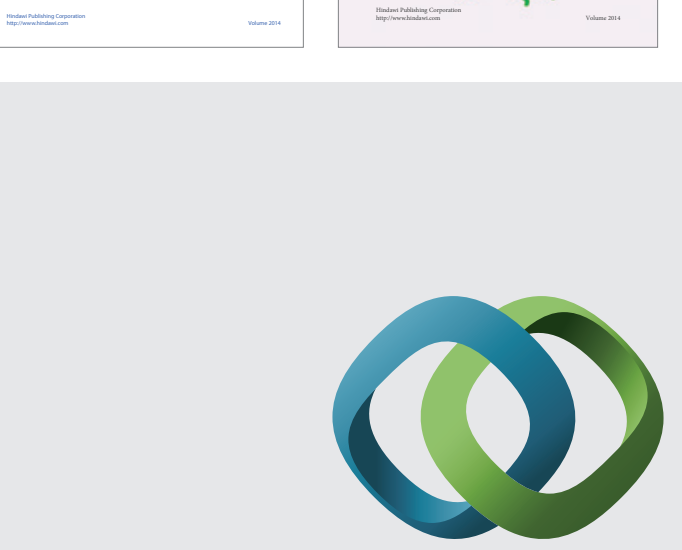

\section{Hindawi}

Submit your manuscripts at

http://www.hindawi.com
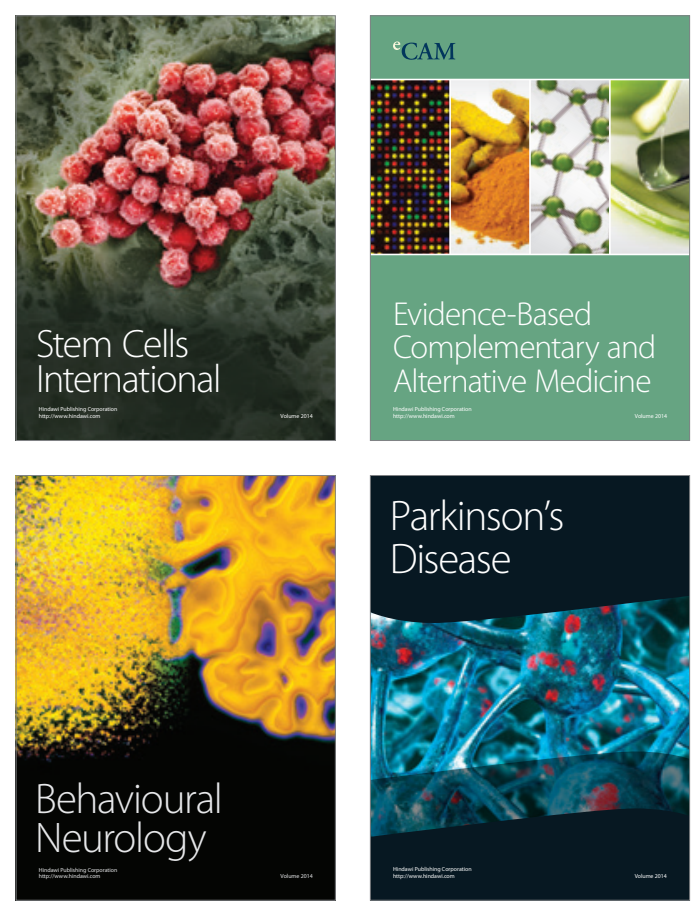

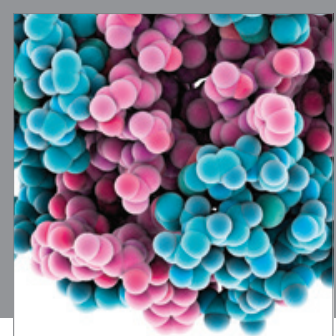

Journal of
Diabetes Research

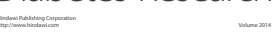

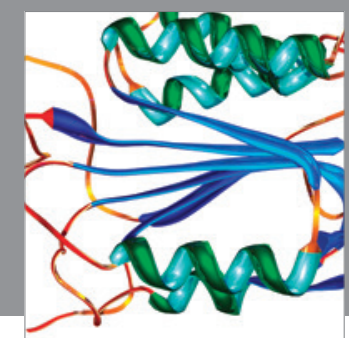

Disease Markers
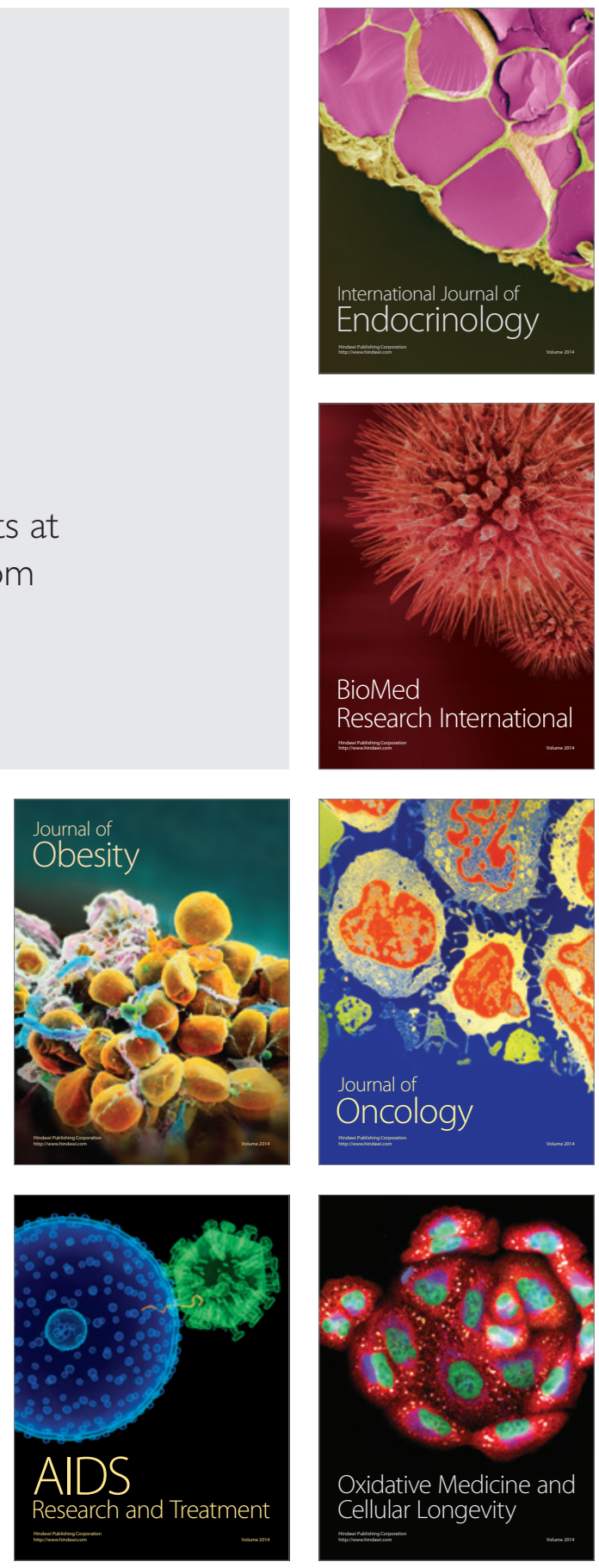